\title{
Linkage and Anomeric Differentiation in Trisaccharides by Sequential Fragmentation and Variable-Wavelength Infrared Photodissociation
}

\author{
Yanglan Tan, Nicolas C. Polfer \\ Department of Chemistry, University of Florida, Gainesville, FL 32611, USA
}

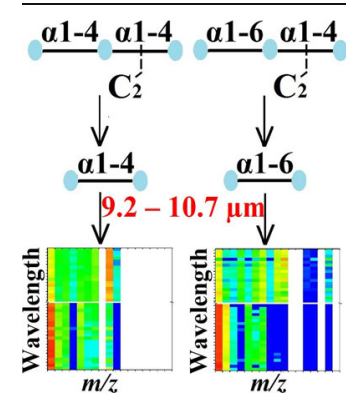

terns of disaccharides with identical glycosidic bonds. Conversely, the photodissociation patterns of different glycosidic linkages exhibit considerable differences. On the basis of these results, the linkage position and anomericity of glycosidic bonds of disaccharide units in trisaccharides can be systematically differentiated and identified, providing a promising approach to characterize the structures of isomeric oligosaccharides.

Keywords: Disaccharide, Trisaccharide, Isomers, Spectral fingerprints, IRMPD, $\mathrm{CO}_{2}$ laser

\begin{abstract}
Carbohydrates and their derivatives play important roles in biological systems, but their isomeric heterogeneity also presents a considerable challenge for analytical techniques. Here, a stepwise approach using infrared multiple-photon dissociation (IRMPD) via a tunable $\mathrm{CO}^{2}$ laser $(9.2-10.7 \mu \mathrm{m})$ was employed to characterize isomeric variants of glucose-based trisaccharides. After the deprotonated trisaccharides were trapped and fragmented to disaccharide $C^{2}$ fragments in a Fourier transform ion cyclotron resonance (FTICR) cell, a further variablewavelength infrared irradiation of the $\mathrm{C}^{2}$ ion produced wavelength-dependent dissociation patterns that are represented as heat maps. The photodissociation patterns of these $C^{2}$ fragments are shown to be strikingly similar to the photodissociation pat-
\end{abstract} Received: 16 September 2014/Revised: 14 October 2014/Accepted: 15 October 2014/Published Online: 10 December 2014

\section{Introduction}

$\mathrm{C}$ arbohydrates and their derivatives are widespread organic compounds in nature, and they play important roles in biological processes. They contribute to the source of energy for life activities and also interact in the biological functions of cell growth, fertilization, inflammation, and cell-cell interactions [1-4]. The number of possible linear and branched carbohydrate isomers is immense, and has been referred to as the isomer barrier [5]. For instance, there are eight possible hexoses in the pyranose form, which differ in the chirality of the hydroxyl group at C-2, C-3, and C-4. Furthermore, for disaccharides and oligosaccharides, variations in saccharide building blocks and sequence, as well as glycosidic linkage positions and anomericity, give rise to a large number of putative isomers. Scheme 1 illustrates the nomenclature for the example

Electronic supplementary material The online version of this article (doi:10.1007/s13361-014-1025-6) contains supplementary material, which is available to authorized users.

Correspondence to: Nicolas C. Polfer; e-mail: polfer@chem.ufl.edu of two glucose saccharide units connected by an $\alpha 1-4$ glycosidic bond.

Carbohydrates thus represent an extreme case of isomeric heterogeneity, requiring analytical techniques that can address this perplexing but crucial challenge. Nuclear magnetic resonance (NMR) is generally considered to be the gold standard in elucidating carbohydrate structures [6-8]. Mass spectrometry (MS) offers the advantages of lower requirements for analysis time, sample quantity, and purity. A key limitation of mass spectrometry, however, is its inability to distinguish isomers based on mass information alone. Strategies for distinguishing isomers have, thus, focused on distinguishing other physical properties [9], such as the collision cross sections of ions, as measured in ion mobility [10-17] experiments, or their fragmentation patterns in collision-induced dissociation (CID) [1823], electron-mediated dissociation [24-26], or laser photodissociation [27-36].

Tunable laser photodissociation allows "action" spectra of ions to be recorded [37]. The premise of this approach rests on resonant absorption of photons to induce photodissociation. Laser spectroscopy combines the structural insights from molecular absorbances with insights from the dissociation chemistry and, thus, provides a wealth of information to 


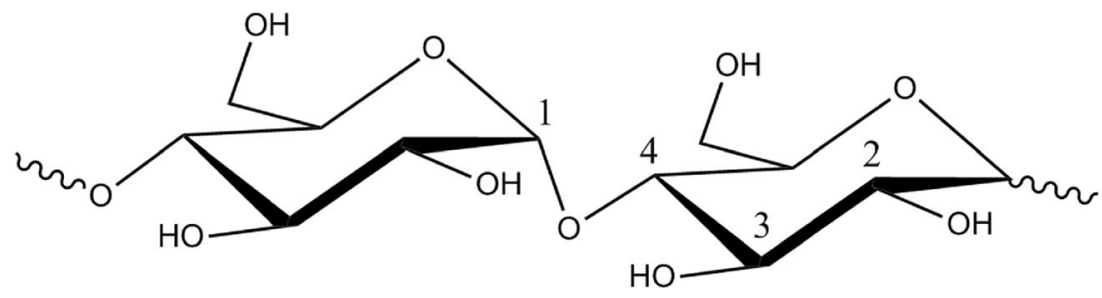

Scheme 1. Chemical structure of Glca1-4Glc glycosidic bond in an oligosaccharide

distinguish isomers. In wavelength-tunable infrared multiplephoton dissociation (IRMPD) of disaccharide isomers, the fragmentation patterns could be considered spectral fingerprints [29, 34].

The charge carrier plays an important role in directing the dissociation chemistry. Protonated oligosaccharides are prone to cleaving exclusively at glycosidic bonds, providing the least structural information [38]. Metal-adducted complexes have been shown to exhibit advantages based on higher ionization efficiencies and more informative fragmentation $[14,20,39]$. For alkali metal adducts, it has been shown that $\mathrm{Li}^{+}$is bound tightest and causes most abundant cross-ring fragmentation [33, 40], rationalizing the prevalent use of lithiated oligosaccharides in positive-mode oligosaccharides MS analysis [18, 19, 29, 30, 34, 41]. For the negative-mode MS analysis, previous studies have shown that $\mathrm{Cl}^{-}$adducts are highly stable and yield high abundances of fragment ions [42-45]. In addition, deprotonated oligosaccharide precursors can be formed efficiently in electrospray ionization (ESI) in the presence of a basic modulator, such as aqueous ammonium acetate $\left(\mathrm{NH}_{4} \mathrm{Ac}\right)$ or ammonium hydroxide $\left(\mathrm{NH}_{4} \mathrm{OH}\right)$ [46, 47]. Finally, chemical modification of oligosaccharides, such as permethylation or chemical modification of the reducing end, assisted by multiple stages of mass isolation and CID (i.e., $\mathrm{MS}^{\mathrm{n}}$ ), has been demonstrated as a promising avenue to characterize the glycosidic bonds in larger oligosaccharides [23, 48, 49].

Note that in the differentiation of isomers in mixtures, separation techniques prior to structural elucidation by dissociation greatly simplify the analysis. Separations can either be carried out in solution by chromatography [50] or in the gas phase by ion mobility [14]. In some information-rich fragmentation data, it may be possible to identify particular isomers in mixtures based on distinctive features, without the need for separation [51]; however, this often involves asking specific structural questions, as well as having some knowledge of the sample that is being analyzed.

In this work, we implement variable-wavelength IRMPD-MS to characterize the glycosidic bonds in unmodified trisaccharides. In a stepwise approach, the trisaccharides are dissociated to disaccharide units, whose rich wavelength-dependent photodissociation patterns can verify the linkage position and anomericity of the disaccharide unit.

\section{Experimental}

\section{Materials}

Disaccharides $\left(\mathrm{C}_{12} \mathrm{H}_{22} \mathrm{O}_{11}\right)$ and trisaccharides $\left(\mathrm{C}_{18} \mathrm{H}_{32} \mathrm{O}_{16}\right)$ comprised of solely D-glucose (Glc) were used, and their nonreducing monosaccharide substructures were in the pyranoside form. Nigerose (Glc $\alpha 1-3 \mathrm{Glc}$ ), maltose (Glc $\alpha 1-4 \mathrm{Glc}$ ), cellobiose (Glc $\beta 1-4 \mathrm{Glc})$, isomaltose (Glc $\alpha 1-6 \mathrm{Glc})$, gentiobiose (Glc $\beta 1-6 \mathrm{Glc})$, laminaritriose (Glc $\beta 1-3 \mathrm{Glc} \beta 1-3 \mathrm{Glc})$, maltotriose (Glc $\alpha 1-4 \mathrm{Glc} \alpha 1-4 \mathrm{Glc})$, cellotriose (Glc $\beta 1-4 \mathrm{Glc} \beta 1$ 4Glc), and panose (Glc $\alpha 1-6 \mathrm{Glc} \alpha 1-4 \mathrm{Glc}$ ) were purchased from Sigma Aldrich (St. Louis, MO, USA). Laminaribiose (Glc $\beta 1$ 3Glc), kojibiose (Glc $\alpha 1-2 \mathrm{Glc}$ ), and sophorose (Glc $\beta 1-2 \mathrm{Glc})$ were purchased from Carbosynth (Compton, Berkshire, UK). ${ }^{18} \mathrm{O}$-labeled water $\left(\mathrm{H}_{2}{ }^{18} \mathrm{O}\right)\left(97\right.$ atom $\left.\%{ }^{18} \mathrm{O}\right)$ was also purchased from Sigma Aldrich (St. Louis, MO). All reagents were used without further purification. Saccharide solutions were prepared at a concentration of $0.1 \mathrm{mM}$ in $\mathrm{MeOH}$ with adding $1 \%$ volume of $\mathrm{NH}_{4} \mathrm{OH}(29.44 \%$ by mass $)$ solution.

\section{${ }^{18} \mathrm{O}$-Labeling of Trisaccharides}

Laminaribriose (Glc $\beta 1-3 \mathrm{Glc}$ ) $1.5 \mathrm{mg}$ was dissolved in $100 \mu \mathrm{L}$ $\mathrm{H}_{2}{ }^{18} \mathrm{O}$ at room temperature for 5 to $7 \mathrm{~d}$ to label the reducing end with ${ }^{18} \mathrm{O}$. The solution was then diluted to $0.1 \mathrm{mM}$ with $\mathrm{MeOH}$ containing $\mathrm{NH}_{4} \mathrm{OH}$ prior to mass spectrometric analysis; $1.5 \mathrm{mg}$ of maltotriose (Glc 1 1-4Glc $\alpha 1-4 \mathrm{Glc}$ ) was also labeled using the same procedure.

\section{Mass Spectrometry and Infrared Multiple Photon Dissociation (IRMPD)}

The saccharide samples were ionized in a commercial electrospray ionization (ESI) source (Analytica of Branford, Branford, CT, USA), coupled to a Bruker 47e FTICR (Fourier transform ion cyclotron resonance) mass spectrometer (Bruker Daltonics, Billerica, MA, USA) equipped with a $4.7 \mathrm{~T}$ superconducting magnet (Magnex Scientific Ltd., Abington, $\mathrm{UK})$. The negative ions were trapped in an Infinity cell and irradiated with a Lasy-20G tunable continuous wave $\mathrm{CO}_{2}$ laser (Access Laser Co., Marysville, WA, USA), as controlled by a mechanical shutter.

To study wavelength-dependent fragmentation patterns, the disaccharide standards were irradiated with the $\mathrm{CO}_{2}$ laser for $500 \mathrm{~ms}$ at a power of $1.5 \mathrm{~W}$. Because of two distinct frequency 
bands of the $\mathrm{CO}_{2}$ laser emission, the laser was tuned over two separate wavelength bands $(9.2-9.7 \mu \mathrm{m}$ and $10.2-10.7 \mu \mathrm{m})$ at 40 specific wavelength channels (see Supplementary Table S-1). Trisaccharides, on the other hand, were broken down stepwise in a two-part experiment. Gas-phase trisaccharide ions were first photodissociated with the $\mathrm{CO}_{2}$ laser for $50 \mathrm{~ms}$ at $9.588 \mu \mathrm{m}$ with a power of $1.5 \mathrm{~W}$, yielding an abundant disaccharide fragment (at $\mathrm{m} / z$ 341); as shown in Supplementary Figure S-1, the ion signal for $\mathrm{C}_{2}$ was optimized under those conditions. The output of the $\mathrm{CO}_{2}$ laser was then switched to a variable wavelength $(9.2-9.7 \mu \mathrm{m}$ and 10.2-10.7 $\mu \mathrm{m}$ ), and after a 4-s time delay (to allow stabilization of the laser output), the mass-isolated disaccharide fragment ions were further photodissociated at this variable wavelength for $500 \mathrm{~ms}$, under the same conditions as the standard disaccharide experiments. Note that the output wavelengths of a $\mathrm{CO}_{2}$ laser are limited by the rovibrational $\mathrm{P}$ and $\mathrm{R}$ branches, and that the output wavelength is selected by virtue of a diffraction grating in the laser cavity. The voltages and timing in the experiment were under control of the Predator program, developed by the National High Magnetic Field Laboratory (NHMFL). TTL (transistor-transistor logic) pulses from the Predator program were employed to trigger the mechanical shutter, as well as an in-house LabView software, which controlled the $\mathrm{CO}_{2}$ laser output wavelength and power. In each experiment, a set of 10 mass spectra were collected and averaged.

Data analysis was performed with the aid of another inhouse LabView program. The normalized abundance ratios of each mass spectral product fragment were calculated and averaged with three replicate measurements. Normalized abundance ratios were expressed by the following equation:

normalized abundance ratio

$$
=\frac{\text { fragment intensity }}{\sum \text { fragment intensities }+ \text { precursor intensity }}
$$

The normalized abundance ratios $(0.0050-0.8000)$ of each fragment as a function of infrared wavelength were plotted as heat maps with a color distribution from pure blue $(0.0050)$ to pure red $(0.8000)$ on a logarithmic scale. Ratios in the trace quantity (0-0.0050) were also presented with pure blue.

\section{Results and Discussion}

\section{Photodissociation Patterns of Disaccharides}

Figure 1 shows the wavelength-variable photodissociation patterns of eight isomeric glucose-containing disaccharides in the form of heat maps. For each disaccharide, the normalized abundance ratios of the observed photodissociation mass channels are given. The abundance ratios of IRMPD fragment ions exhibit considerable differences over the wavelength range of the $\mathrm{CO}_{2}$ laser. Those ions generated by glycosidic cleavage (i.e., $m / z 161$ and 179) and other high-mass fragments are dominant in the higher wavelength range from 10.2 to $10.7 \mu \mathrm{m}$. In contrast, low-mass fragments, including $\mathrm{m} / \mathrm{z} 101$, 113 , and 115, yield high abundances in the lower wavelength range from 9.2 to $9.7 \mu \mathrm{m}$. The higher extent of fragmentation, and likely sequential fragmentation, in the latter range can be explained by strong photon absorbance attributable to $\mathrm{C}-\mathrm{O}$ stretch vibration in this range.

Previous studies have demonstrated the use of diagnostic fragment ions that can identify the linkage position of the glycosidic bond for the case of lithiated disaccharides [18, 19, $29,34]$. Table 1 summarizes the appearance of various photodissociation products in the case of deprotonated disaccharides (based on the data shown in Figure 1). For instance, $m / z 263$ is a unique ion produced from 1-2-linked disaccharides, whereas the ions, $m / z 191$ and 215 are generated exclusively from dissociation of disaccharides with a 1-3 linkage. The fragments at $m / z 221$ and 281 are obtained as diagnostic product ions from photodissociation of the two 1-6 linkage anomers of isomaltose (Glc $\alpha 1-6 \mathrm{Glc})$ and gentiobiose (Glc $\beta 1-6 \mathrm{Glc})$. As a general observation, the larger photofragments from $\mathrm{m} / \mathrm{z} 191$ to 323 are found to be diagnostic, whereas the smaller fragments except $\mathrm{m} / \mathrm{z} 149$ appear for all isomers.

Besides specific product ions, diagnostic ratios of key ions over variable wavelengths contain much information in order to differentiate the linkage and anomericity of disaccharide isomers. For the 1-4-linked maltose (Glcal-4Glc) and cellobiose (Glc $\beta 1-4 \mathrm{Glc})$, which are the only pair with identical product ions, the wavelength-dependent abundance ratios of specific low-mass fragments such as $m / z 101$ and 113 show some differences at the IR range of $10.2-10.7 \mu \mathrm{m}$ and provide the means to differentiate them. Also, the normalized abundance ratio of $m / z 161$ fragment of maltose (Glc $\alpha 1-4 \mathrm{Glc}$ ) varies from 0.3 to 0.4 at the range of $10.2-10.4 \mu \mathrm{m}$, whereas at the same range the abundance ratio of $\mathrm{m} / \mathrm{z} 161$ is about $0.5-0.8$ for cellobiose (Glc $\beta 1-4 \mathrm{Glc})$.

\section{Reproducibility}

It is worth noting that the reproducibility of these heat maps depends on a number of experimental parameters, including the alignment of the laser, the laser output power, and the irradiation time. Consistent laser alignment and irradiation time were set up, and output power was kept at $1.50 \pm 0.05 \mathrm{~W}$ for disaccharide standard experiments. As an example, the day-to-day difference between two wavelength-variable photodissociation experiments for isomaltose (Glcal-6Glc) is displayed in Supplementary Figure S-2, showing the measurements on two separate days (i.e., measurements 1 and 2). The two measurements are found to be strikingly similar. In order to illustrate the similarities of both measurements, the results are also depicted as a difference heat map, where the numerical results for measurement 2 are subtracted from those in measurement 1 . If the patterns matched exactly, the whole figure would be green (i.e., no or minor differences). Indeed, the majority of the difference heat map is green, and only negligible 

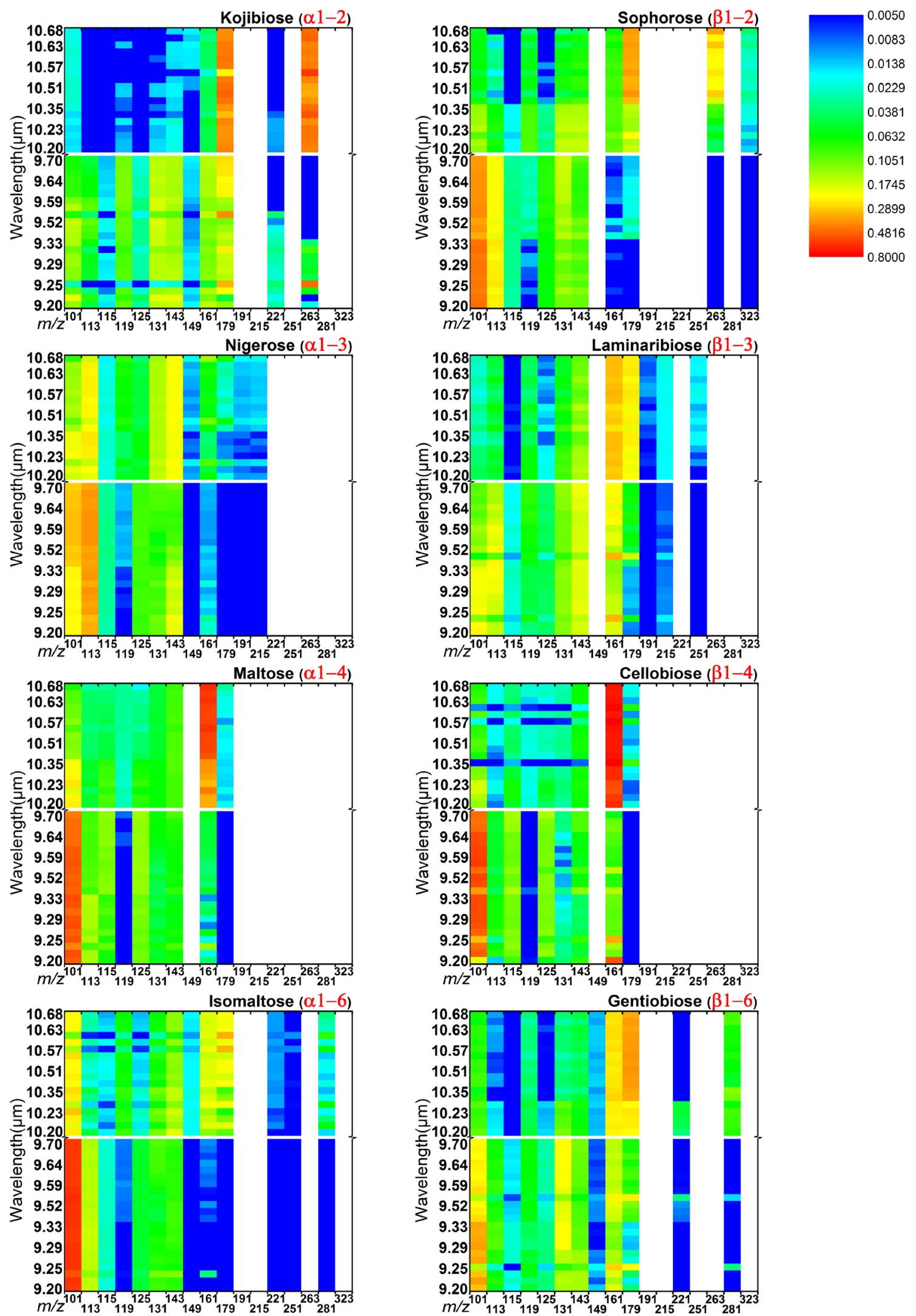

Figure 1. Heat maps of wavelength-dependent infrared photodissociation of isomeric disaccharide standards, showing the normalized abundance ratios of the photofragment mass channels as a function of $\mathrm{CO}_{2}$ laser wavelength. The abundance ratios $(0.0050-0.8000)$ are represented in the color range between pure blue (low) to pure red (high) on a logarithmic scale. Nonobservable photofragment channels are denoted by white 
Table 1. Appearance of Photodissociation Fragment Ions for Isomeric Deprotonated Disaccharides (Diagnostic Fragments Indicated by Shading)

\begin{tabular}{|c|c|c|c|c|c|c|c|c|}
\hline$m / z$ & $\begin{array}{l}\text { Kojibiose } \\
\text { (Glcal-2Glc) } \\
\end{array}$ & $\begin{array}{l}\text { Sophorose } \\
\text { (Glc } \beta 1-2 \mathrm{Glc}) \\
\end{array}$ & $\begin{array}{l}\text { Nigerose } \\
\text { (Glca1-3Glc) } \\
\end{array}$ & $\begin{array}{l}\text { Laminaribiose } \\
\text { (Glc } \beta 1-3 \mathrm{Glc} \text { ) } \\
\end{array}$ & $\begin{array}{l}\text { Maltose } \\
\text { (Glc } \alpha 1-4 \mathrm{Glc}) \\
\end{array}$ & $\begin{array}{l}\text { Cellobiose } \\
\text { (Glc } \beta 1-4 \mathrm{Glc}) \\
\end{array}$ & $\begin{array}{l}\text { Isomaltose } \\
\text { (Glcal-6Glc) } \\
\end{array}$ & $\begin{array}{l}\text { Gentiobiose } \\
\text { (Glc } \beta 1-6 \mathrm{Glc}) \\
\end{array}$ \\
\hline 101 & + & + & + & + & + & + & + & + \\
\hline 113 & + & + & + & + & + & + & + & + \\
\hline 115 & + & + & + & + & + & + & + & + \\
\hline 119 & + & + & + & + & + & + & + & + \\
\hline 125 & + & + & + & + & + & + & + & + \\
\hline 131 & + & + & + & + & + & + & + & + \\
\hline 143 & + & + & + & + & + & + & + & + \\
\hline 149 & + & & + & & & & + & + \\
\hline 161 & + & + & + & + & + & + & + & + \\
\hline 179 & + & + & + & + & + & + & + & + \\
\hline 191 & & & + & + & & & & \\
\hline 215 & & & + & + & & & & \\
\hline 221 & + & & & & & & + & + \\
\hline 251 & & & & + & & & + & \\
\hline 263 & + & + & & & & & & \\
\hline 281 & & & & & & & + & + \\
\hline 323 & & + & & & & & & \\
\hline
\end{tabular}

differences are seen, mainly for the $m / z 101$ product, showing that the experimental conditions can be reproduced faithfully.

In order to better illustrate the fidelity of relative photofragment channel abundances in terms of differentiating isomeric species, selected photofragment channels for maltose and cellobiose are shown in Supplementary Figure S3. The mean and standard deviation values from triplicate measurements indicate that many of the differences in photofragment abundances are reliably reproduced, allowing those isomeric species to be told apart.

\section{Dissociation of Trisaccharides}

When glucose-containing trisaccharides $(\mathrm{m} / \mathrm{z} 503)$ are irradiated and dissociated by a $\mathrm{CO}_{2}$ laser, of particular interest is the disaccharide fragment at $m / z 341\left(\mathrm{C}_{12} \mathrm{H}_{22} \mathrm{O}_{11}\right)$. To determine whether, in the negative mode, $\mathrm{m} / \mathrm{z} 341$ originates from cleavage of either the reducing or nonreducing termini of the trisaccharide precursors (i.e. $\mathrm{C}_{2}$ or $\mathrm{Y}_{2}$ fragments according to Domon and Costello's systematic nomenclature [52]) (see Scheme 2), the carbonyl oxygen atom of the reducing end was labeled with ${ }^{18} \mathrm{O}[21,53]$. With the laser irradiation by the $\mathrm{CO}_{2}$ laser at a fixed wavelength of $9.588 \mu \mathrm{m}$, the photodissociation spectra of ${ }^{18} \mathrm{O}$-labeled [laminaritriose-H] ${ }^{-}(\mathrm{m} / \mathrm{z}$ $505)$ and ${ }^{18} \mathrm{O}$-labeled [maltotriose-H] ${ }^{-}(\mathrm{m} / \mathrm{z} 505)$ were obtained and are depicted in Figure 2. Both spectra of ${ }^{18} \mathrm{O}$-labeled $[\text { laminaritriose- } \mathrm{H}]^{-}$and [maltotriose- $\left.\mathrm{H}\right]^{-}$show that exclusively the $m / z 341$ product ion was observed, whereas there was no evidence for the corresponding fragment at $\mathrm{m} / \mathrm{z} 343$. In other

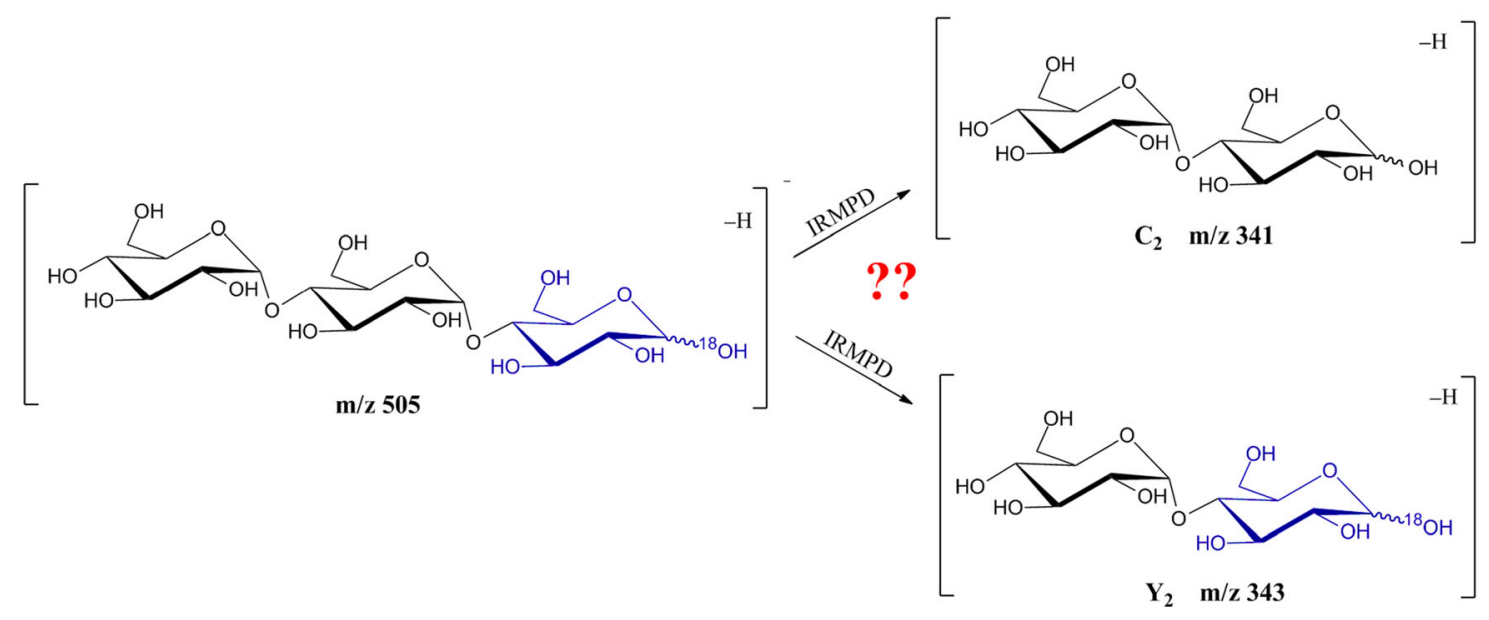

Scheme 2. Dissociation of ${ }^{18} \mathrm{O}$-labeled trisaccharide to $\mathrm{C}_{2}$ and $\mathrm{Y}_{2}$ fragments 
(a)

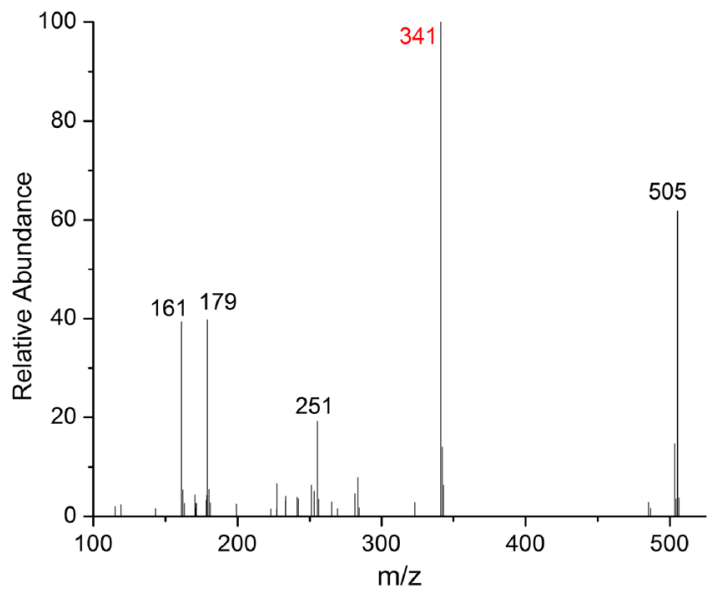

(c)

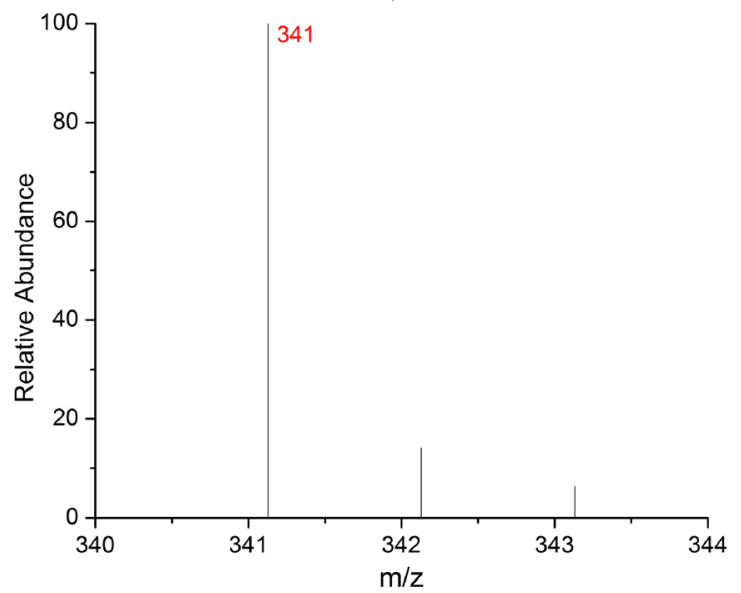

(b)

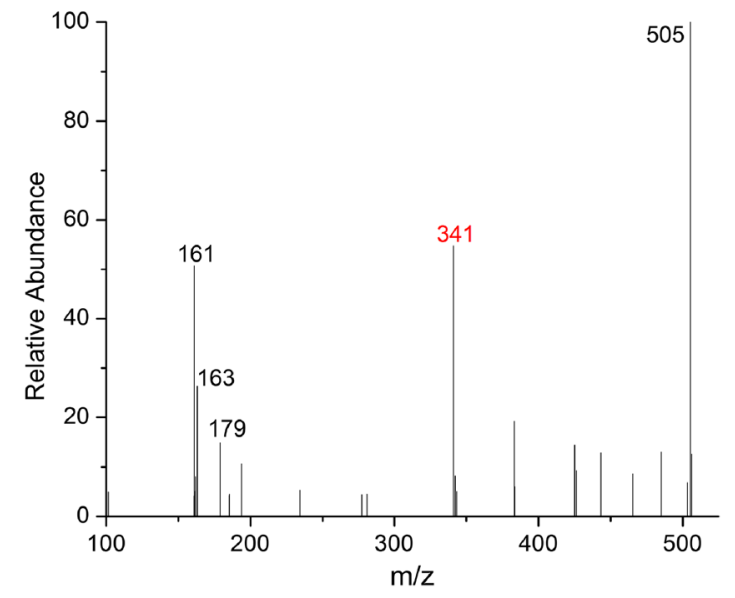

(d)

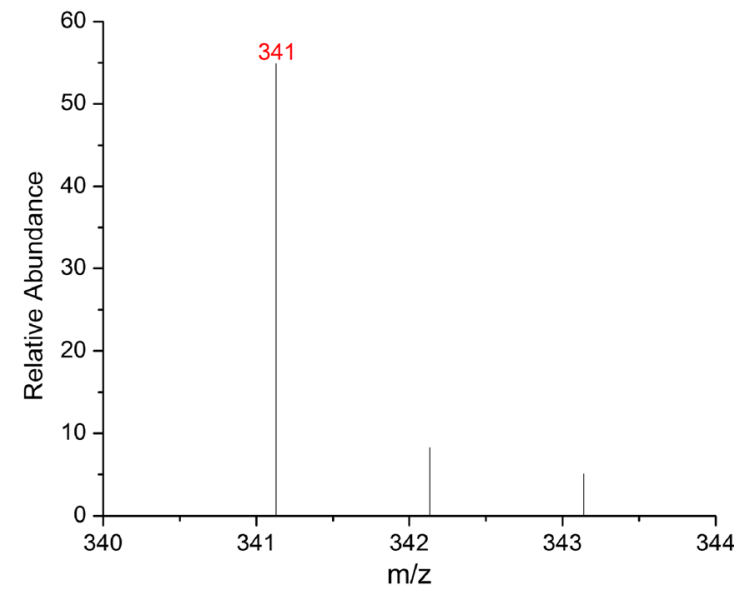

Figure 2. The photodissociation mass spectra for ${ }^{18} \mathrm{O}$-labeled [laminaritriose- $\left.\mathrm{H}\right]^{-}$(a), (c) and ${ }^{18} \mathrm{O}-$ labeled [maltotriose- $\left.\mathrm{H}\right]^{-}$(b), (d)

words, these control experiments confirmed that the trisaccharides incurred cleavage between the second and third residue, giving rise to the $C_{2}$ fragment, and not to the isomeric $Y_{2}$ product ion. As a side note, $m / z 161$ and 163 are observed as abundant fragments for [maltotriose-H] ${ }^{-}$, whereas only $\mathrm{m} / z 161$ is seen for [laminaritriose-H] $]^{-}$. The $m / z 161$ and 163 ions can be rationalized by $B_{1}$ and $Z_{1}$, respectively. The $Z_{1}$ fragment is, in principle, the complementary fragment from $\mathrm{C}_{2}$. It is not clear whether $\mathrm{B}_{1}$ occurs from direct dissociation of the trisaccharide precursor or consecutive dissociation of $\mathrm{C}_{2}$.

\section{Photodissociation of Disaccharide Units Derived from Trisaccharides}

As the key fragment at $m / z 341\left(\mathrm{C}_{12} \mathrm{H}_{22} \mathrm{O}_{11}\right)$ corresponds to a $\mathrm{C}_{2}$ ion, a more detailed structural probing of $\mathrm{C}_{2}$, in principle, allows one to establish the nature of the glycosidic bond between residues 1 and 2 in the original trisaccharide precursor. For this purpose, $\mathrm{C}_{2}$ ions from various trisaccharides were subjected to variable-wavelength photodissociation, and these results were compared with reference wavelength-dependent

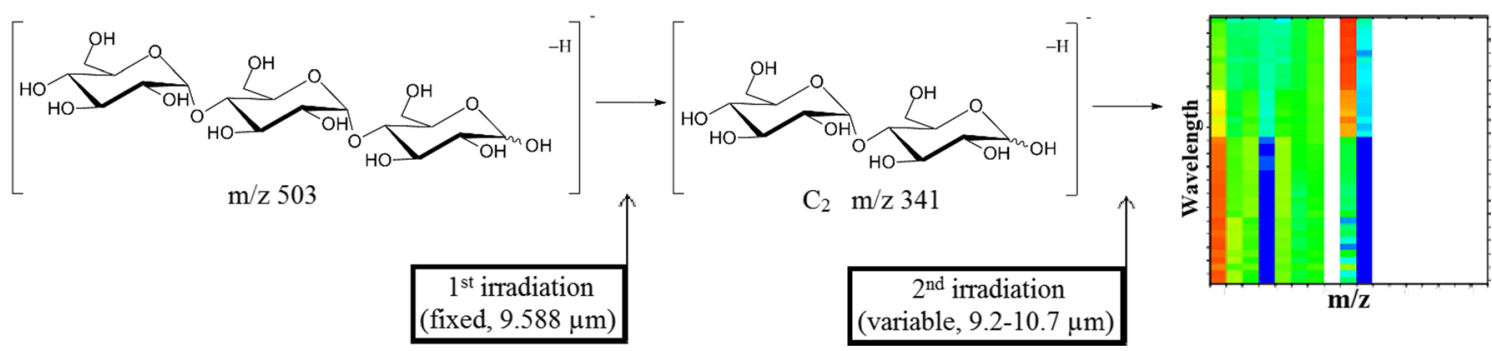

Scheme 3. Stepwise fragmentation for deprotonated trisaccharides 

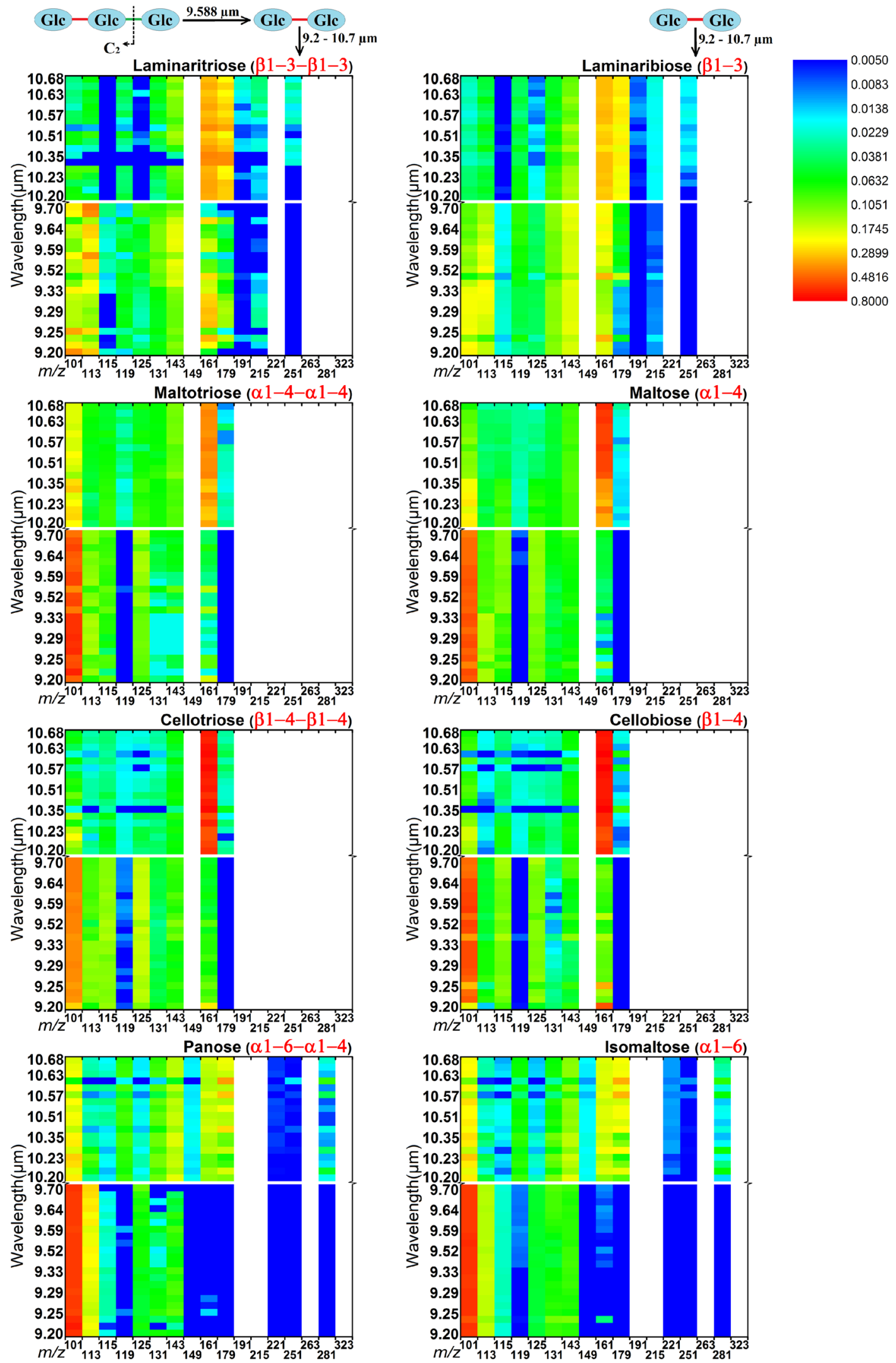

Figure 3. Heat maps of wavelength-dependent infrared photodissociation of $\mathrm{C}_{2}$ fragments derived from trisaccharides (left) and matching disaccharide standards, showing the normalized abundance ratios of the photofragment mass channels as a function of $\mathrm{CO}_{2}$ laser wavelength. The abundance ratios $(0.0050-0.8000)$ are represented in the color range between pure blue (low) to pure red (high) on a logarithmic scale. Nonobservable photofragment channels are denoted by white 
photodissociation patterns of disaccharides. Scheme 3 illustrates the strategy of this two-step approach, involving fixedwavelength irradiation to generate $\mathrm{C}_{2}$ from the trisaccharide precursor, followed by variable-wavelength photodissociation of the $\mathrm{C}_{2}$ ion.

Control experiment showed that generation of the $\mathrm{C}_{2}$ fragment was optimized for short irradiation times (i.e., $50 \mathrm{~ms}$ ) at a moderate power (i.e., $1.5 \mathrm{~W}$ ). As shown in Supplementary Figure S-1, under these conditions the yield of $\mathrm{C}_{2}$ was maximized at a wavelength of 9.588 $\mu \mathrm{m}$. In the stepwise dissociation scheme above, the fixed wavelength of the first irradiation was thus set to 9.588 $\mu \mathrm{m}$, followed by mass isolation of the $\mathrm{C}_{2}$ ion, and a variable wavelength for the second irradiation. For the second irradiation, since the wavelength irradiation time and power are critical factors in determining the dissociation patterns, these parameters had to be kept consistent with the conditions used for the disaccharide standards. It was found that a 4-s time delay between the first and second irradiations minimized fluctuations when switching the laser wavelength.

Figure 3 compares heat maps for wavelengthdependent photodissociation patterns of $\mathrm{C}_{2}$ ions (from four isomeric trisaccharides) with reference photodissociation patterns of disaccharide standards. As expected, heat maps of the $\mathrm{C}_{2}$ ions match most closely those disaccharide standards with the same chemical structures. For instance, $C_{2}$ from laminaritriose (Glc $\left.\beta 1-3 \mathrm{Glc} \beta 1-3 \mathrm{Glc}\right)$ has the same glycosidic linkage and fragmentation pattern as laminaribiose $(\mathrm{Glc} \beta 1-3 \mathrm{Glc})$, whereas $\mathrm{C}_{2}$ from panose (Glc $\alpha 1-6 \mathrm{Glc} \alpha 1-4 \mathrm{Glc})$ is identical to isomaltose (Glc $\alpha 1-$ 6Glc). Even differences in chirality, such as in the case of maltotriose (Glc $\alpha 1-4 \mathrm{Glc} \alpha 1-4 \mathrm{Glc})$ and cellotriose (Glc $\beta 1-4 \mathrm{Glc} \beta 1-4 \mathrm{Glc})$, are well differentiated in these measurements, as some distinct patterns in the dissociation products of $\mathrm{m} / \mathrm{z} 101,113,119$, and 161 are reproduced. As an example of how closely the patterns resemble each other, the heat maps for $\mathrm{C}_{2}$ from panose (Glco1-6Glc $\alpha 1-$ 4Glc) and the disaccharide isomaltose (Glca1-6Glc) are subtracted from each other and are represented as a difference heat map (see Supplementary Figure S-4). In this case, the wavelength range from 10.2 to $10.7 \mu \mathrm{m}$ is largely green, light blue, or yellow and, thus, reflects only minor differences. There are, however, some notable differences in the range from 9.6 to $9.8 \mu \mathrm{m}$ for the $\mathrm{m} / z 113$ and 131 fragments. These differences are a manifestation of different conditions in the experiment leading to irreproducibility. As a general observation, the wavelength region from 10.2 to $10.7 \mu \mathrm{m}$ appears to be more reliable and, thus, likely to be more useful in terms of pattern recognition. In the lower wavelength region, the range from 9.3 to $9.4 \mu \mathrm{m}$ also appears to be well reproducible and yields complementary information.

These measurements also have important repercussions on the chemistry that takes place in sequential fragmentation of saccharides. While nominally, a $\mathrm{C}_{2}$ fragment from a larger oligosaccharide corresponds to the same building block as a reference disaccharide, the present experiments in fact give strong evidence that these structures are chemically equivalent. The dissociation of larger entities into fragments may, in principle, proceed via a number of chemical pathways involving rearrangement reactions and, thus, giving rise to complex product ion structures; complex rearrangement chemistry has been attested in numerous studies on peptide fragmentation pathways $[54,55]$, which can complicate structural analysis. It appears that such concerns are not merited in the case of oligosaccharide dissociation, where the glycosidic bond and other chemical moieties are conserved upon ion activation [21].

Finally, although this study has confirmed that disaccharide building blocks can be identified based on their photofragmentation patterns, these proof-of-principle experiments were carried out for pure solutions of the analytes in question. The analysis of real-world, complex mixtures requires separation techniques prior to structural probing, as already alluded to in Section 1 .

\section{Conclusions}

In this study, a series of isomeric forms of glucose trisaccharides were ionized in negative ion mode (as deprotonated anions), and were characterized by wavelength-variable infrared photodissociation using a tunable $\mathrm{CO}_{2}$ laser. The main conclusions from this work were:

- Photodissociation of trisaccharide ions yielded effective glycosidic cleavage between the second and third residues (i.e., $\mathrm{C}_{2}$ fragments), as verified by ${ }^{18} \mathrm{O}$ isotope labeling on the reducing end.

- $\mathrm{C}_{2}$ photofragment yield was maximized for short (50 ms) irradiation at $9.588 \mu \mathrm{m}$.

- Variable-wavelength photodissociation of these $C_{2}$ ions resulted in characteristic photodissociation patterns represented here as heat maps. These heat maps were found to be almost identical to those generated in control experiments for corresponding disaccharide ions, indicating a close structural similarity between both.

The stepwise dissociation employed in these measurements allowed a structural elucidation of linkage and anomericity of glycosidic bonds in trisaccharides; this strategy also provides a step towards a reliable and practical tandem MS analysis of oligosaccharides, where their substructures can then be confirmed by variable-wavelength IRMPD, particularly if combined with chemical labeling of the reducing end.

\section{Acknowledgments}

This research is financially supported by the National Science Foundation under grant CHE-1403262. The NHMFL, and in particular Dr. Gregory Blakney, is acknowledged for help with installing the Predator software. 
Conflict of Interest. The authors declare no competing financial interest.

\section{References}

1. Taylor, M.E., Drickamer, K.: Introduction to glycobiology. Oxford University Press, Oxford, UK. 123-239 (2003)

2. Dwek, R.A.: Glycobiology: toward understanding the function of sugars. Chem. Rev. 96, 683-720 (1996)

3. Varki, A.: Biological roles of oligosaccharides - all of the theories are correct. Glycobiology 3, 97-130 (1993)

4. Lis, H., Sharon, N.: Lectins: carbohydrate-specific proteins that mediate cellular recognition. Chem. Rev. 98, 637-674 (1998)

5. Laine, R.A.: A calculation of all possible oligosaccharide isomers both branched and linear yields $1.05 \times 10^{12}$ structures for a reducing hexasaccharide - the isomer-barrier to development of single-method saccharide sequencing or synthesis systems. Glycobiology 4, 759-767 (1994)

6. Bush, C.A., Martin-Pastor, M., Imberty, A.: Structure and conformation of complex carbohydrates of glycoproteins, glycolipids, and bacterial polysaccharides. Annu. Rev. Biophys. Biomol. Struct. 28, 269-293 (1999)

7. Bendiak, B., Fang, T.T., Jones, D.N.M.: An effective strategy for structural elucidation of oligosaccharides through NMR spectroscopy combined with peracetylation using doubly ${ }^{13} \mathrm{C}$-labeled acetyl groups. Can. J. Chem. 80, 1032-1050 (2002)

8. Armstrong, G.S., Bendiak, B.: High-resolution four-dimensional carboncorrelate ${ }^{1} \mathrm{H}-{ }^{1} \mathrm{H}$ roesy experiments employing isotags and the filter diagonalization method for effective assignment of glycosidic linkages in oligosaccharides. J. Magn. Reson. 181, 79-88 (2006)

9. Kailemia, M.J., Ruhaak, L.R., Lebrilla, C.B., Amster, I.J.: Oligosaccharide analysis by mass spectrometry: a review of recent developments. Anal. Chem. 86, 196-212 (2014)

10. Liu, Y.S., Clemmer, D.E.: Characterizing oligosaccharides using injectedion mobility mass spectrometry. Anal. Chem. 69, 2504-2509 (1997)

11. Wu, C., Siems, W.F., Asbury, G.R., Hill, H.H.: Electrospray ionization high-resolution ion mobility spectrometry-mass spectrometry. Anal. Chem. 70, 4929-4938 (1998)

12. Hoaglund-Hyzer, C.S., Clemmer, D.E.: Ion trap/ion mobility/quadrupole/ time of flight mass spectrometry for peptide mixture analysis. Anal. Chem. 73, 177-184 (2001)

13. Clowers, B.H., Dwivedi, P., Steiner, W.E., Hill, H.H., Bendiak, B.: Separation of sodiated isobaric disaccharides and trisaccharides using electrospray ionization-atmospheric pressure ion mobility-time of flight mass spectrometry. J. Am. Soc. Mass Spectrom. 16, 660-669 (2005)

14. Lee, S., Valentine, S.J., Reilly, J.P., Clemmer, D.E.: Analyzing a mixture of disaccharides by IMS-VUVPD-MS. Int. J. Mass Spectrom. 309, 161-167 (2012)

15. Li, H., Giles, K., Bendiak, B., Kaplan, K., Siems, W.F., Hill Jr., H.H.: Resolving structural isomers of monosaccharide methyl glycosides using drift tube and traveling wave ion mobility mass spectrometry. Anal. Chem. 84, 3231-3239 (2012)

16. Li, H., Bendiak, B., Siems, W.F., Gang, D.R., Hill Jr., H.H.: Carbohydrate structure characterization by tandem ion mobility mass spectrometry (IMMS) ${ }^{2}$. Anal. Chem. 85, 2760-2769 (2013)

17. Huang, Y., Dodds, E.D.: Ion mobility studies of carbohydrates as group I adducts: isomer specific collisional cross section dependence on metal ion radius. Anal. Chem. 85, 9728-9735 (2013)

18. Zhou, Z.R., Ogden, S., Leary, J.A.: Linkage position determination in oligosaccharides - MS/MS study of lithium-cationized carbohydrates. J. Org. Chem. 55, 5444-5446 (1990)

19. Hofmeister, G.E., Zhou, Z., Leary, J.A.: Linkage position determination in lithium-cationized disaccharides-tandem mass-spectrometry and semiempirical calculations. J. Am. Chem. Soc. 113, 5964-5970 (1991)

20. Asam, M.R., Glish, G.L.: Tandem mass spectrometry of alkali cationized polysaccharides in a quadrupole ion trap. J. Am. Soc. Mass Spectrom. 8, 987-995 (1997)

21. Fang, T.T., Bendiak, B.: The stereochemical dependence of unimolecular dissociation of monosaccharide-glycolaldehyde anions in the gas phase: a basis for assignment of the stereochemistry and anomeric configuration of monosaccharides in oligosaccharides by mass spectrometry via a key discriminatory product ion of disaccharide fragmentation, $m / z$ 221. J. Am. Chem. Soc. 129, 9721-9736 (2007)

22. Ashline, D.J., Lapadula, A.J., Liu, Y.H., Lin, M., Grace, M., Pramanik, B., Reinhold, V.N.: Carbohydrate structural isomers analyzed by sequential mass spectrometry. Anal. Chem. 79, 3830-3842 (2007)
23. Ashline, D.J., Hanneman, A.J.S., Zhang, H.L., Reinhold, V.N.: Structural documentation of glycan epitopes: sequential mass spectrometry and spectral matching. J. Am. Soc. Mass Spectrom. 25, 444- 453 (2014)

24. Kailemia, M.J., Li, L.Y., Xu, Y.M., Liu, J., Linhardt, R.J., Amster, I.J.: Structurally informative tandem mass spectrometry of highly sulfated natural and chemoenzymatically synthesized heparin and heparan sulfate glycosaminoglycans. Mol. Cell. Proteomics 12, 979-990 (2013)

25. Wolff, J.J., Laremore, T.N., Aslam, H., Linhardt, R.J., Amster, I.J.: Electron-induced dissociation of glycosaminoglycan tetrasaccharides. J. Am. Soc. Mass Spectrom. 19, 1449-1458 (2008)

26. Wolff, J.J., Leach, F.E., Laremore, T.N., Kaplan, D.A., Easterling, M.L., Linhardt, R.J., Amster, I.J.: Negative electron transfer dissociation of glycosaminoglycans. Anal. Chem. 82, 3460-3466 (2010)

27. Xie, Y.M., Lebrilla, C.B.: Infrared multiphoton dissociation of alkali metalcoordinated oligosaccharides. Anal. Chem. 75, 1590-1598 (2003)

28. Lancaster, K.S., An, H.J., Li, B.S., Lebrilla, C.B.: Interrogation of N-linked oligosaccharides using infrared multiphoton dissociation in FT-ICR mass spectrometry. Anal. Chem. 78, 4990-4997 (2006)

29. Polfer, N.C., Valle, J.J., Moore, D.T., Oomens, J., Eyler, J.R., Bendiak, B.: Differentiation of isomers by wavelength-tunable infrared multiple-photon dissociation-mass spectrometry: application to glucose-containing disaccharides. Anal. Chem. 78, 670-679 (2006)

30. Stefan, S.E., Eyler, J.R.: Differentiation of methyl-glucopyranoside anomers by infrared multiple photon dissociation with a tunable $\mathrm{CO}_{2}$ laser. Anal. Chem. 81, 1224-1227 (2009)

31. Racaud, A., Antoine, R., Joly, L., Mesplet, N., Dugourd, P., Lemoine, J.: Wavelength-tunable ultraviolet photodissociation (UVPD) of heparinderived disaccharides in a linear ion trap. J. Am. Soc. Mass Spectrom. 20, 1645-1651 (2009)

32. Racaud, A., Antoine, R., Dugourd, P., Lemoine, J.: Photoinduced dissociation of heparin-derived oligosaccharides controlled by charge location. J. Am. Soc. Mass Spectrom. 21, 2077-2084 (2010)

33. Fukui, K., Takahashi, K.: Infrared multiple photon dissociation spectroscopy and computational studies of O-glycosylated peptides. Anal. Chem. 84, 2188-2194 (2012)

34. Stefan, S.E., Eyler, J.R.: Differentiation of glucose-containing disaccharides by infrared multiple photon dissociation with a tunable $\mathrm{CO}_{2}$ laser and Fourier transform ion cyclotron resonance mass spectrometry. Int. J. Mass Spectrom. 297(1/3), 96-101 (2010)

35. Devakumar, A., Thompson, M.S., Reilly, J.P.: Fragmentation of oligosaccharide ions with $157 \mathrm{~nm}$ vacuum ultraviolet light. Rapid Commun. Mass Spectrom. 19, 2313-2320 (2005)

36. Reilly, J.P.: Ultraviolet photofragmentation of biomolecular ions. Mass Spectrom. Rev. 28, 425-447 (2009)

37. Polfer, N.C., Dugourd, P.: Laser photodissociation and spectroscopy of mass-separated biomolecular ions. Springer, Switzerland. 13-19 (2013)

38. Ngoka, L.C., Gal, J.F., Lebrilla, C.B.: Effects of cations and charge types on the metastable decay-rates of oligosaccharides. Anal. Chem. 66, 692-698 (1994)

39. da Costa, E.V., Moreira, A.S.P., Nunes, F.M., Coimbra, M.A., Evtuguin, D.V., Domingues, M.R.M.: Differentiation of isomeric pentose disaccharides by electrospray ionization tandem mass spectrometry and discriminant analysis. Rapid Commun. Mass Spectrom. 26, 2897-2904 (2012)

40. Grant, E.R., Schulz, P.A., Sudbo, A.S., Shen, Y.R., Lee, Y.T.: Is multiphoton dissociation of molecules a statistical thermal process. Phys. Rev. Lett. 40, 115-118 (1978)

41. Simoes, J., Domingues, P., Reis, A., Nunes, F.M., Coimbra, M.A., Domingues, R.M.: Identification of anomeric configuration of underivatized reducing glucopyranosyl-glucose disaccharides by tandem mass spectrometry and multivariate analysis. Anal. Chem. 79, 5896-5905 (2007)

42. Jiang, Y.J., Cole, R.B.: Oligosaccharide analysis using anion attachment in negative mode electrospray mass spectrometry. J. Am. Soc. Mass Spectrom. 16, 60-70 (2005)

43. Zhu, J.H., Cole, R.B.: Ranking of gas-phase acidities and chloride affinities of monosaccharides and linkage specificity in collision-induced decompositions of negative ion electrospray-generated chloride adducts of oligosaccharides. J. Am. Soc. Mass Spectrom. 12, 1193-1204 (2001)

44. Guan, B., Cole, R.B.: MALDI linear-field reflectron TOF post-source decay analysis of underivatized oligosaccharides: determination of glycosidic linkages and anomeric configurations using anion attachment. J. Am. Soc. Mass Spectrom. 19, 1119-1131 (2008)

45. Boutegrabet, L., Kanawati, B., Gebefuegi, I., Peyron, D., Cayot, P., Gougeon, R.D., Schmitt-Kopplin, P.: Attachment of chloride anion to 
sugars: mechanistic investigation and discovery of a new dopant for efficient sugar ionization/detection in mass spectrometers. Chem. Eur. J. 18, 13059-13067 (2012)

46. Mulroney, B., Traeger, J.C., Stone, B.A.: Determination of both linkage position and anomeric configuration in underivatized glucopyranosyl disaccharides by electrospray mass-spectrometry. J. Mass Spectrom. 30, 1277-1283 (1995)

47. Konda, C., Bendiak, B., Xia, Y.: Differentiation of the stereochemistry and anomeric configuration for 1-3-linked disaccharides via tandem mass spectrometry and ${ }^{18}$ O-labeling. J. Am. Soc. Mass Spectrom. 23, 347-358 (2012)

48. Ashline, D., Singh, S., Hanneman, A., Reinhold, V., Ashline, D., Singh, S., Hanneman, A., Reinhold, V.: Congruent strategies for carbohydrate sequencing. 1. Mining structural details by MS ${ }^{\mathrm{n}}$. Anal. Chem. 77, 6250-6262 (2005)

49. Konda, C., Londry, F.A., Bendiak, B., Xia, Y.: Assignment of the stereochemistry and anomeric configuration of sugars within oligosaccharides via overlapping disaccharide ladders using $\mathrm{MS}^{\mathrm{n}}$. J. Am. Soc. Mass Spectrom. 25, 1441-1450 (2014)

50. Paulus, A., Klockow, A.: Detection of carbohydrates in capillary electrophoresis. J. Chromatogr. A 720, 353-376 (1996)
51. Bin Oh, H., Leach, F.E., Arungundram, S., Al-Mafraji, K., Venot, A., Boons, G.J., Amster, I.J.: Multivariate analysis of electron detachment dissociation and infrared multiphoton dissociation mass spectra of heparan sulfate tetrasaccharides differing only in hexuronic acid stereochemistry. J. Am. Soc. Mass Spectrom. 22, 582-590 (2011)

52. Domon, B., Costello, C.E.: A systematic nomenclature for carbohydrate fragmentations in Fab-MS/MS spectra of glycoconjugates. Glycoconj. J. 5, 397-409 (1988)

53. Fang, T.T., Zirrolli, J., Bendiak, B.: Differentiation of the anomeric configuration and ring form of glucosyl-glycolaldehyde anions in the gas phase by mass spectrometry: isomeric discrimination between $\mathrm{m} / \mathrm{z} 221$ anions derived from disaccharides and chemical synthesis of $\mathrm{m} / \mathrm{z} 221$ standards. Carbohydr. Res. 342, 217-235 (2007)

54. Paizs, B., Bythell, B.J., Maitre, P.: Rearrangement pathways of the $a_{4}$ ion of protonated YGGFL characterized by IR spectroscopy and modeling. J. Am. Soc. Mass Spectrom. 23, 664-675 (2012)

55. Tirado, M., Polfer, N.C.: Defying entropy: forming large head-to-tail macrocycles in the gas phase. Angew. Chem. Int. Ed. 51, 6436-6438 (2012) 